\title{
Flexible cognitive control and two human signal systems
}

\author{
Elastyczność kontroli poznawczej a dwa układy sygnałowe u człowieka
}

\author{
Mariya Mun ${ }^{1}$, Sveta Berdibayeva ${ }^{1}$, Dariyakul Kozhamzharova², Sholpan Satiyeva ${ }^{3}$, \\ Agaisha Mursaliyeva ${ }^{4}$, Bibianar Baizhumanova ${ }^{5}$ \\ ${ }^{1}$ Al-Farabi Kazakh National University, Almaty, Kazakhstan \\ ${ }^{2}$ Taraz State Pedagogical Institute, Taraz, Kazakhstan \\ ${ }^{3}$ Shakarim State University of Semey, Semey, Kazakhstan \\ ${ }^{4}$ Aktobe Regional State University named after K. Zhubanov, Aktobe, Kazakhstan \\ ${ }^{5}$ Eurasian National University named after L.N. Gumilev, Astana, Kazakhstan \\ Neuropsychiatria i Neuropsychologia 2016; 11, 3: 99-105
}

Address for correspondence:

ass. prof. Mariya Mun

Al-Farabi Kazakh National University

050038 al-Farabi Avenue 71

Almaty, Kazakhstan

e-mail: mmaria.876@gmail.com

\section{Abstract}

Aim of the study: The authors attempt to determine the relationship between flexibility of cognitive control and features of the nervous system in the context of two human signal systems.

Material and methods: The authors used the Stroop test, the method of determining the balance of the first and the second signal systems in the context of visual memory, and two heuristic tasks: the verbal task "Swahili" and the visual-figurative task "Observer in the square".

Results: There were no direct correlations between flexible cognitive control and the first/second signal systems, or their balance. However, an important connection between the second signal system and the predominance of the verbal (semantic-conceptual) method of processing information. The results of the correlation analysis have proven the existence of a link between flexible cognitive control and successful solutions of heuristic tasks. In the group of "Rigid" subjects, the successful solution of tasks is associated with a dominant manner of the processing of the information, and the presentation of a particular task.

Conclusions: The results obtained demonstrate a link between flexible cognitive control and successful solutions of heuristic tasks. They also point to a relationship between solving visual-figurative tasks and sensory-perceptual (perceptual-motor) methods of processing information. There were no direct correlations between flexible cognitive control and the first/second signal systems or their balance.

Key words: flexible cognitive control, cognitive style, signal systems of higher nervous activity (HNA), heuristic tasks.

\section{Introduction}

The activity of thinking is a lively and flexible one, consisting of continuous mutual transitions of images and logic. Vekker (2000) applied the notion of an "alphabet" of thinking for the interpretation of the thinking process itself. $\mathrm{He}$ stressed that "thinking as a process is a continuous reversible transfer of information from the language of simultaneous-spatial gestalts, submitted by images at different levels of generality, in the symbolic-operator language, submitted by dimensional successive structures of speech signals".

The idea of cross-language translation stems from the postulate of the unity of the sensuous and logical levels of reflections and knowledge of reality. A change of thinking alphabets (from figurative to logical, and vice versa) as a general psychological phenomenon is present in the process of knowledge in each person.

The mutual transitions from one "alphabet" of thinking to another are carried out continuously/subtly, and their experimental registration is complex. Our assumption is that the dynamics of the process of continuous interaction between the two main components of thinking can be reflected in the cognitive style of "rigid-flexible cognitive control", the essence of which is the figurative-logic translation of information, or a switch from one alphabet to another. Thus, the flexibility of cognitive control is considered to be an internal mechanism of mental activity. We share the point of view of Kholodnaya (2002), stating that cognitive styles are meta-capacities defining, not only the 
productive performance, but also the individual characteristics of information processing. We believe that the flexibility of cognitive control is organically embedded in the personality mechanisms of real world knowledge.

In our work, we propose an empirical approach to address this issue. First, we attempt to determine the relationship of flexibility and features of the nervous system.

If we consider flexible cognitive control as the ability, naturally, the question about its makings (inborn qualities, basics, etc.) arises. The individual uniqueness of people's abilities is conditioned by the development of the makings of these abilities. The physiologist Pavlov (1951) believes that the makings are manifested in features of specific human types of higher nervous activity (HNA). He considered signaling systems as the basis of the specific human types of HNA. The function of the first signal system, which is inherent in both animals and humans, is in reaction to signals of external objects that act on their receptor apparatus, and are held in the appropriate cells of the central nervous system.

The second signal system, inherent to humans only, is understood as the ability to respond to the signals of the second degree (i.e., signals of primary signals, which exist solely in the form of words). Interrelations of the first and second signal systems are a measure of the separation of subjects into three basic types: "artists" (the relative dominance of the first signal system), "thinkers" (relative predominance of the second signal system), and representatives of the middle type (relative balance between the first and second signal systems). The distinguishing features of "artists" are that "they capture the reality of the whole, entirely, in full, living reality, without crushing, without separation" (Pavlov 1951), and are characterized by a brightness of immediate impressions, memory, and richness of imagination; these people are mostly writers, musicians, painters, etc. "Thinkers usually crush reality, sacrifice it, making of it some temporary frame, and then gradually reassembled parts and attempt to revive them" (Pavlov 1951). Thinkers are characterized by activity of analysis, systematization and abstraction in mental activity. We assume that the signal systems are considered as makings (inborn qualities, basics, etc.) of mental ability to move from figurative to logical thinking alphabets.

Teplov (1998), following Pavlov, considers the properties of the nervous system as direct physiological bases of individual personality traits, including general abilities. "Typological properties of the nervous system are part of the makings/inborn qualities, and are part of the natural foundations of abilities' development. Perhaps they even occupy an important place in the structure of these natural prerequisites of abilities" (Teplov 1998). Under the properties of the nervous system, he understands the nature, but not necessarily the hereditary formations, suggesting that they may be the result of fetal development, or the development of conditions during the first period of human life.

Golubeva (1997, 2005), based on the main points of the Teplov theory, creates a model of personality structure. Based on this model, the temperament is determined by the properties of the nervous system that are common to both humans and animals, and abilities are determined by specific human qualities of the nervous system. However, she notes that "because of hemispheric differentiation properties that are common to humans and animals, often acting as the "relevant" inborn basis of temperament, they may also "serve" non-verbal or verbal functions", relating to the general cognitive abilities. Thus, the properties of the nervous system can be considered a basis for both general abilities and temperament.

The concept of the existence of particular interactions among the general and the special properties of the human nervous system is actively being investigated. Pechenkov (1997) experimentally substantiated the position that, "on the psychological level, the interaction of general and specific human types of HNA may occur in combinations of certain features of the emotional and cognitive sides of psychic activity - emotional and cognitive systems".

Based on the foregoing, we make several assumptions:

1. Flexible cognitive control should be connected to the features of specific human types of higher nervous activity - the first and second signal systems, as a kind of makings/inborn qualities.

2. The high flexibility allows subjects to deal with heuristic tasks in the most successful and productive manner.

In this experimental study we determine relations of flexible cognitive control and two human signal systems in the process of solving two heuristic tasks (with imaginative and logical presentation of the conditions).

\section{Material and methods}

\section{Sample}

The sample comprised third-year students from Al-Farabi Kazakh National University, Faculty of Philosophy and Political Science, 
Department of Philosophy and Department of Psychology $(N=53,29$ female and 24 male, average age $=22.5$ years).

\section{Test procedures}

1. Stroop test (Kholodnaya 2002; Dormashev et al. 2003; Mouratidis et al. 2001).

This test was developed for the diagnosis of cognitive style rigid-flexible cognitive control. "This cognitive style characterizes the degree of subjective difficulties in changing the different ways of processing information in a situation of cognitive conflict. Rigid control indicates difficulties in the transition from verbal functions in sensory-perceptual due to the low degree of automation, while flexible indicates the relative ease of this transition due to the high degree of automation" (Kholodnaya 2002).

Three cards are sequentially shown to the subject. The first card contains words for names of four colors (the subject is required to read the words as soon as possible) (W-Card). The second card contains multicolored stars of the same colors (the subject must name the color of the stars as quickly as possible) (C-Card). The third card contains color names that are written in different colors, and the name does not match the color of the ink. For example, the word "red" written in yellow ink (the subject must name the color of the written words' ink as quickly as possible) (CW-card). The main index (i.e. indicator of interference) is the time difference in performing the CW-card (color of the word) and C-card (color). The greater the cognitive control rigidity, the greater the interference. Conversely, low interference indicators suggest the flexibility of cognitive control.

On the Stroop test, we calculate an additional indicator of "Verbal", proposed by Broverman. This is a quotient between the performance time of the $2^{\text {nd }}$ card (C-Card) and the $1^{\text {st }}$ card (W-Card). High values of this indicator are evidence of the predominance of verbal (semantic-conceptual) methods of processing information, while low values reflect the predominance of sensory-perceptual (perceptual-motor) methods of processing information (Kholodnaya 2002).

The Stroop test is commonly employed in experimental psychological studies of perception, attention, memory, thinking (the productivity of problem solving, decision making and thinking strategies) and personality (MacLeod 1991; Dormashev et al. 2003; Mouratidis et al. 2001).

There is evidence that the Stroop test "does not reveal the actual effects of perceptual inter- ference, but rather diagnoses the manifestation of the effect of interference on a higher level of information processing, namely, the verbal response training level" (Zinchenko and Kireyeva 1986), i.e., at the level of semantic interference. Moreover, activation of the left anterior division of the cerebral cortex (Mouratidis et al. 2001) was experimentally demonstrated during the performance of the Stroop test. These findings suggest the possibility of using the Stroop test to diagnose mental flexibility.

2. The method of determining the balance of the first and the second signal systems in the context of visual memory, designed by Borisova (1956).

This technique was originally made in line with the concepts of Pavlov (1951), and is intended to diagnose the individual balance of the first and second signal systems. However, the continued use of this technique in psychological practice has demonstrated that such a diagnosis is not limited to its ability. Antonova (1965) applied this method and concluded that the levels of the development of imaginative and logical thinking correspond to those of the first and second signal systems respectively. This method is actively applied for the diagnosis of specific human types of HNA ("artist" and "thinker" types) (Pechenkov 1997). Thus, we conclude that the method of Borisova (1956) reveals the balance of imaginative and logical components of thinking by identifying the balance of the first and second signal systems.

This method consists of two main series. In the first series, after a three-second exposure of a contour image of a tree leaf, the subject needs to find it among 10 similar images. This series consists of five tasks to be solved by manipulating visual-shaped components. In the second series, there is a 10-second exposure of the image of a tree leaf with other images. The subject must describe the image accurately, and on the basis of this description, it can be isolated from a sample of 10 other images. This series also includes five tasks of verbal-actualizing logical components (a description of the perceived visual image). The test is evaluated by one point for each correct decision (i.e. the correct recognition). The balance of points received for both series characterizes the relationship of visual-figurative and verbal-logical components of intellectual activity.

3. Two heuristic tasks, designed by Kulyutkin and Suhobskaya (1971): 1) verbal task "Swahili", and 2) visual-figurative task, "Observer in the square". 
The independent variables are the flexibility of cognitive control, and levels of development of imaginative and logical components of thinking, which are defined on the basis of the dominance of the first or the second signal system. The dependent variable is the success of the two heuristic tasks.

\section{Results}

I. As a result of the method of Borisova (1956), subjects were divided into three groups: 1) a balance of visual-figurative and verbal-logical components (40 people); 2) the relative prevalence of verbal and logical components of intellectual activity (12 people); and $3)$ the relative predominance of visual-shaped components of intellectual activity (1 person). It can be assumed that the balanced group (about the same level of development of figurative and verbal components of thinking) is seen most frequently based on the results, hence, the main condition of university studies. The predominance of the verbal component in a group of 14 people can testify that it is easier for people to work in sign systems, with verbal materials. An interesting fact is that, among the entire sample, only one person has revealed the predominance of the figurative component of verbal thinking. Perhaps modern higher education mainly develops verbal-logical thinking.

After a word-color Stroop interference test was conducted, our sample was divided into "Flexible" and "Rigid". The separation process of "Flexible" and "Rigid" was carried out by using the median criterion (Kholodnaya 2002). The validity of this choice was mathematically proven by comparing the interference indices via an independent-samples $t$-test $(t=8.7$, $p<0.001, t$ critical $=3.5$ ).

Since the sample size of 53 people is odd, further analysis excluded the protocol containing a median value equal to 1.78 in the parameter "rigid-flexible cognitive control". Therefore, there were 26 flexible and 26 rigid subjects in total.

Of the 40 "balanced" subjects (in Borisova's method), 22 were flexible, and 17 rigid (in the Stroop test); from 13 "Non-balance" subjects, 4 flexible and rigid 9 subjects were identified.

The angular Fisher transformation hypothesis was confirmed as follows:

1) The number of "Flexible" subjects in the "Balance" group was greater than in the "Non-balance" group; $F$-test $=1.64(p<0.05)$.
2) The number of "Rigid" subjects in the "Non-balance" group was greater than in the "Balance" group; $F$-test $=1.64(p<0.05)$.

Thus, the number of "Flexible" subjects in the "Balance" group was significantly higher than among the "Non-balance" group. The "Non-balance" subjects were characterized by a tendency to rigidity.

We compared the "Balance"/"Non-balance" and rigid/flexible subjects in the success in solving heuristic tasks by using angular Fisher transformation. The results of this comparison are shown in Table 1.

Conclusions on the method of Borisova: According to the table, the "Balance" subjects cope more easily with heuristic tasks compared to subjects with the imbalance of the first and second signal systems. Hence, this "Balance" contributes to the successful solution of problems in both languages of thinking (imaginative and logical); $F$-test $=1.85(p<0.05)$. There were no significant differences in the successful solution of 1 heuristic task and the complete absence of solutions between "Balance" and "Non-balance" subjects.

Conclusions on the Stroop test: flexible subjects were more successful in solving the two heuristic tasks; $F$-test $=4.13(p<0.01)$. Rigid subjects were much more likely to solve only one heuristic task $(F$-test $=3.08, p<0.01)$ or not solve any $(F$-test $=1.79, p<0.05)$.

Thus, we can conclude that flexibility has a positive effect on the success in heuristic tasks. Flexibility enables the subject to easily "jump" from one information "alphabet" to the other.

II. To answer the question of how the flexible cognitive control (Stroop test) is connected with the imaginative and logical components of thinking (method of Borisova), and the success in solving heuristic tasks, we correlated all these indicators via Spearman's method. The results yielded by the correlation analysis are presented in Table 2 .

1) There were no significant correlations between the flexibility of cognitive control and first/second signal systems or their balance. Perhaps this is a consequence of the small volume or the specifics of our sample. After all, in psychological research, there is evidence of a positive connection between the Stroop test and the Brain Integration Scale (Travis and Lagrosen 2014), and even a 30$60 \%$ heritability estimate for the Stroop test, suggesting a significant genetic component (Nanasi et al. 2012). 
Table 1. "Balance"/“Non-balance” and "Rigid”/“Flexible” subjects in solving heuristics tasks

\begin{tabular}{|c|c|c|c|c|c|c|}
\hline & \multicolumn{2}{|c|}{ Method of Borisova } & \multirow[t]{2}{*}{$F$-test } & \multicolumn{2}{|c|}{ Stroop test } & \multirow[t]{2}{*}{$F$-test } \\
\hline & $\begin{array}{l}\text { "Balance" } \\
(N=40)\end{array}$ & $\begin{array}{c}\text { "Non-balance" } \\
(N=13)\end{array}$ & & $\begin{array}{l}\text { "Flexible" } \\
(N=26)\end{array}$ & $\begin{array}{l}\text { "Rigid" } \\
(N=26)\end{array}$ & \\
\hline $\begin{array}{l}\text { The successful solution } \\
\text { of } 2 \text { heuristic tasks }\end{array}$ & $24(60 \%)$ & $4(31 \%)$ & $1.85(p<0.05)$ & $21(81 \%)$ & $7(27 \%)$ & $4.13(p<0.01)$ \\
\hline $\begin{array}{l}\text { The successful solution } \\
\text { of } 1 \text { heuristic task }\end{array}$ & $12(30 \%)$ & $7(54 \%)$ & 1.54 & $4(15 \%)$ & $14(54 \%)$ & $3.08(p<0.01)$ \\
\hline $\begin{array}{l}\text { Lack of solution of } \\
2 \text { heuristic tasks }\end{array}$ & 4 (10\%) & $2(15 \%)$ & 0.47 & $1(4 \%)$ & 5 (19\%) & $1.79(p<0.05)$ \\
\hline
\end{tabular}

The numbers in the cells of the table indicate the number of subjects.

The parentheses show the calculated corresponding percentages.

Table 2. Correlations between Stroop test, method of Borisova and successful solutions of heuristic tasks

\begin{tabular}{|c|c|c|c|c|}
\hline & $\begin{array}{l}\text { Indicator of } \\
\text { "Verbal", proposed } \\
\text { by Broverman }\end{array}$ & $\begin{array}{l}\text { Verbal task } \\
\text { "Swahili" }\end{array}$ & $\begin{array}{l}\text { Visual-figurative } \\
\text { task "Observer in } \\
\text { the square" }\end{array}$ & $\begin{array}{l}\text { Successful } \\
\text { solutions of two } \\
\text { heuristic tasks }\end{array}$ \\
\hline First signal system & NS & NS & NS & NS \\
\hline Second signal system & $\begin{array}{c}0.250^{*} \\
(p<0.05)\end{array}$ & NS & NS & NS \\
\hline Balance of 1 and 2 signal systems & NS & NS & NS & NS \\
\hline Flexibility of cognitive control & NS & $\begin{array}{l}-0.520^{* *} \\
(p<0.01)\end{array}$ & NS & $\begin{array}{l}-0.515^{* *} \\
(p<0.01)\end{array}$ \\
\hline $\begin{array}{l}\text { Indicator of "Verbal", proposed by } \\
\text { Broverman }\end{array}$ & NS & NS & $\begin{array}{l}-0.427^{* *} \\
(p<0.01)\end{array}$ & NS \\
\hline
\end{tabular}

2) There was a significant correlation between the second signal system and the indicator of "Verbal", proposed by Broverman $(r=0.250$, $p<0.05)$. Therefore, the relative predominance of the second signal system ("thinker" type according to Pavlov) connects to high values of this indicator of "Verbal" or the predominance of the verbal (semantic-conceptual) method of processing information. This is a very specific and important scientific result, which indicates the special (or indirect) connection between signal systems and cognitive style "rigid-flexible cognitive control".

3) There were no significant correlations between the first/second signal systems or their balance, and the successful solution of the heuristic tasks. This suggests that the success of task-solving is not determined by the levels of development of the figurative and logical components of thinking, identified based on the dominance of the first or the second signal system. Thus, flexibility is a more significant indicator for the success of mental activity by the decision of the heuristic tasks than balance of the first and second signal systems.

4) There was a significant correlation between flexibility of cognitive control and successful solutions of the two heuristic tasks $(r=$
$-0.515, p<0.01$, where a negative sign denotes the pole of the flexibility in the cognitive style). Thus, the success in heuristic task solving is high when the index of rigidity is lower. This is consistent with modern data: faster resolution of conflict in the Stroop task, and a reliable measure of frontal executive thinking, support the role of frontal areas in creative processing (Travis and Lagrosen 2014; Zabelina and Robinson 2010).

5) There was a significant correlation between flexibility of cognitive control and success of verbal "Swahili" task solving $(r=-0.520$, $p<0.01)$. This suggests that the greater the flexibility of cognitive control, the more successful is the solution of the verbal task.

6) There was a significant correlation between a successful visual-figurative task "Observer in the square" solution and the indicator of "Verbal", proposed by Broverman D $(r=$ $-0.427, p<0.01$ ).

As previously indicated, high values of this indicator are evidence of the predominance of the verbal (semantic-conceptual) method of processing information, and low values reflect the predominance of the sensory-perceptual (perceptual-motor) method of processing information (Kholodnaya 2002). Consequently, the 
success in solving the visual-figurative task will be greater if the subject is characterized by the predominance of a sensory-perceptual (perceptual-motor) method of processing information.

Based on these results, we suggested that the "Rigid" subjects can successfully solve heuristic tasks if they correspond to their predominance method of processing information. This assumption was confirmed based on the significant correlation between the predominance method of processing information and the successful visual-figurative task "Observer in the square" solution $(r=-0.688, p<0.01)$ in the group of "rigid" subjects $(n=26)$. This means that the smaller Indicator of "Verbal" (i.e. the closer it is to the sensory-perceptual (perceptual-motor)), the more successful "Rigid" subjects are in visual-figurative task solutions.

There were no significant correlations between the predominance method of processing information and successful heuristic tasks in the group of "Flexible" subjects $(n=26)$. Therefore, the predominance method of processing information has no particular meaning for the group of "Flexible" subjects.

We compared the subgroups of "Flexible" and "Rigid" subjects in the total success of the two heuristic tasks. Flexible subjects more successfully coped with the decision of heuristic tasks compared to their rigid counterparts (Mann-Whitney $U=168.5$, significant at $p<0.01$ ).

\section{Discussion}

As a result of our experimental study new data on the relationships of the first and second human signal systems, the cognitive style of "rigid-flexible cognitive control" and the success in solving two heuristic tasks were obtained. The hypothesis that the flexible cognitive control should be associated with the features of specific human types of higher nervous activity - the first and second signal systems - was not experimentally confirmed. However, it was found that the "Flexible" subjects at any ratio of the first and second signal systems were more successful than "Rigid" ones. Thus, flexibility is a more significant indicator for the success of mental activity by the decision of heuristic tasks than balance of the first and second signal systems.

Kholodnaya (2002), the leading researcher of cognitive styles, repeatedly wrote about the absence of experimental data on the relationship of the cognitive style of "rigid-flexible cognitive control" and intellectual success. These data were obtained in the present experimental study.
An important result of the connection between a successful visual-figurative task solution and the indicator of "Verbal", proposed by Broverman, has been obtained for the first time, both on the entire sample level and in the subgroup of "Rigid" subjects. This gives us an opportunity to consider the indicator of "Verbal" in a new way. This indicator is particularly important in conditions of underdevelopment of flexibility. It allows the "Rigid" subjects to successfully solve heuristic tasks, if they correspond to their predominance method of processing information.

Druzhinin (2001) proposed a model of Available Cognitive Resource to explain the high success in solving the problems addressed to productive thinking. This resource "allows the subject to go beyond the field of task, look at it from the outside, turn the cognitive constants in the variable or enter a new additional dimension in the cognitive space" (Druzhinin 1999). Thus, the function of the "available" cognitive resource is to extend the "field of view" of the subject and bring new information. This author also proposed the hypothesis of "Functional Redundancy". He believes that Cognitive Functional Redundancy (CFR) is possessed in varying degrees by all normal members of the human population. CFR means a functional redundancy of cognitive resources in relation to adaptation problems. That is, "the intellectual abilities of a normal person exceed the natural environment's requirements" (Druzhinin 1999). Accordingly, the CFR is embodied in all sorts of creative manifestations. The idea of "Available Cognitive Resource" proposed by Druzhinin (2001) is perfectly consistent with our understanding of Flexibility as figurative-logic translation of information, or a switch from one alphabet to another in the process of task solving. Thus, the essence of creative thinking is seen in the presence of an "available" cognitive resource, excessive in relation to the complexity of the problem, that "allows the individual to go beyond the field of task, introducing new elements, etc. to bring more information and distant analogies". Druzhinin (2001) suggests that "the set of active and available cognitive elements determines the power of cognitive resource and is manifested in the intellectual productivity index" and "high-speed characteristics of intellectual activity are derived from the power of cognitive resource". Accordingly, the operational descriptors of cognitive resource are such simultaneous-speed performance characteristics as the iconic memory and choice reaction time. That is, the author considers it possible to 
link the level of cognitive resource to the level of creativity.

\section{Conclusions}

1. There were no direct correlations between flexible cognitive control and the first/second signal systems or their balance. However, there was a connection between the second signal system and predominance of verbal (semantic-conceptual) methods of processing information.

2. The results of the correlation analysis demonstrate the existence of a link between flexible cognitive control and successful solutions of heuristic tasks.

3. There is a relationship between success in solving visual-figurative tasks and sensory-perceptual (perceptual-motor) methods of processing information.

4. A statistically significant difference was found between heuristic task solutions for "Flexible" and "Rigid" subjects.

5. Within the "Rigid" subgroup there was a connection between the dominance of the sensory-perceptual (perceptual-motor) method of processing information and the successful solution of visual-figurative tasks. The successful solution of tasks was provided with the concurrence of a dominant way of processing information, and a way of the presentation of the task at hand. For "Flexible" subjects, the way of presentation of a task does not affect the success of the solution.

\section{References}

1. Antonova GP. On the relation between individual differences in mental activity of pupils and the peculiarities of their HNA. Questions of Psychology 1965; 6: 53-76.

2. Borisova MN. Method of determining the relation of the first and second signal systems in a visual memory. Nauchnaya Literatura, Moscow 1956.

3. Dormashev UB, Romanov VY, Shilko RS. Interaction of attention and short-term memory: mnemonic effect of Stroop (Post I). Psychol J 2003; 24: 72-79.

4. Druzhinin V.N. Cognitive abilities: the structure, diagnostics, development. Moscow-Saint Petersburg 2001.

5. Druzhinin V.N. Metaphorical models of intelligence. Psychol J 1999; 20: 44-52.

6. Golubeva EA. Abilities. Personality. Individuality. Phoenix, Dubna 2005.

7. Golubeva EA. Research of abilities and personality in the light of the ideas of B.M. Teplov. Nauchnaya Literatura, Dubna 1997.

8. Kholodnaya MA. Cognitive styles: On the nature of individual mind. PER SE, Moscow 2002.

9. Kulyutkin YN, Suhobskaya GS. Individual differences in mental activity of adult learners. Feniks, Moscow 1971.

10. MacLeod CM. Half a Century of Research on the Stroop Effect: An Integrative Review. Psychol Bull 1991; 109: 163-203.
11. Mouratidis M, Bolla K, Funderbunk F, et al. Brain activation and the Stroop color-word interference task: Implications for assessment and treatment. J Psychother Ind Pract 2001; 2: 25-36.

12. Nanasi T, Katonai ER, Sasvari-Szekely M, Szekely A. A Stroop teszt genetikai vonatkozásai [Genetic aspects of the Stroop test]. Neuropsychopharmacologia Hungarica 2012; 14: 252-258.

13. Pavlov IP. A sample of the physiological understanding of the symptomatology of hysteria. Complete set of works. Musl, Moscow-Leningrad 1951.

14. Pechenkov VV. Problems of Individuality: the general and specific human types of HNA. Nauchnaya Literatura, Dubna 1997.

15. Teplov BM. On the study of the properties of the nervous system and psychological manifestations. Nauka, Voronezh 1998.

16. Travis F, Lagrosen Y. Creativity and brain-functioning in product development engineers: a canonical correlation analysis. Creativity Res J 2014; 26: 239-243.

17. Vekker LM. Psyche and Reality: A Unified Theory of psychological processes. Psihologiya, Moscow 2000.

18. Zabelina D, Robinson M. Creativity as flexible cognitive control. Psychology of Aesthetics, Creativity and the Arts 2010; 4: 136-143.

19. Zinchenko TP, Kireyeva NN. On the nature of the effect of interference and the individual characteristics of its display. Tallinn 1986. 